ARoueología Y SocIEDAD

NNo 26, 2013: 111-116

ISSN: 0254-8062

RECIBIDO: 25 / MAR. / 2013

ACEPTADO: 10 / MAY. / 2013

\title{
ESTELAS DE CHAVÍN: DOS AVES SAGRADAS EN EL MUSEO DE ARQUEOLOGÍAY ANTROPOLOGÍA DE SAN MARCOS
}

\author{
VIRGILIO FREDDY CABANILLAS* \\ UNIVERSIDAD NACIONAL MAYOR DE SAN MARCOS \\ peruanticuario@yahoo.es
}

\section{RESUMEN}

Damos cuenta del hallazgo de piezas de litoescultura andina en una colección privada de arte, concretamente fragmentos de dos estelas de la cultura Chavín. Luego de su identificación, las esculturas fueron donadas al Museo de Arqueología y Antropología de la UNMSM.

Palabras Clave: Cultura Chavín, arte Chavín, litoescultura.

\section{Abstract}

We account for the finding of pieces of Andean stone sculpture in a private collection of art, specifically two stelae fragments of the Chavin culture. After identification, the sculptures were donated to the Museum of Archaeology and Anthropology UNMSM.

KeYwoRDS: Chavin culture, Chavin art, stone sculpture.

\section{El HALLAZGo}

«[...] junto a este pueblo de Chavín hay un gran edificio de piedras muy labradas de notable grandeza; era huaca, y santuario de los más famosos de los gentiles, como entre nosotros Roma o Jerusalén adonde venían los indios a ofrecer, y hacer sus sacrificios; porque el demonio en este lugar les declaraba muchos oráculos, y así acudían de todo el reino; hay debajo de tierra grandes salas y aposentos, tanto que hay cierta noticia que pasan por debajo del río, que pasa junto a la huaca o santuario antiguo.

Tienen noticia que en ella hay gran riqueza, y tesoro en oro, y plata, y otras piedras preciosas y aunque muchos han intentado buscar este tesoro por justos juicios de Dios, no han dado con él, por ser grandísima la máquina del edificio [...]».

* Historiador. Magister en Arte Peruano y Latinoamericano. Docente de la EAP de Historia, Facultad de Ciencias Sociales, UNMSM. 
Así se expresaba don Antonio Vázquez de Espinoza (1948: 458) al referirse al centro arqueológico de Chavín de Huántar, cuya antigua grandeza todavía era recordada en el siglo XVII. El comentario es certero, tanto al describir la complejidad del monumento como al anotar su función ritual. Interesa también la referencia al huaqueo de los monumentos arqueológicos, aunque en este caso la arquitectura dificultaba el saqueo.

Un texto posterior describe:

«[...] un subterráneo muy angosto, que aseguran las personas que se metieron con vela hasta una distancia considerable, que conducía a la otra banda por debajo del río. De este conducto se han sacado varios huaqueros ${ }^{1}$, vasos de piedra, instrumentos de cobre y de plata, y un esqueleto de un indio sentado.» (Mariano Eduardo de Rivero 1841: 23).

Muchos de los tesoros del viejo santuario han sido sacados a la luz a lo largo de los siglos -tal como se relata en Antigüedades peruanas- y ahora se conservan en los museos e incluso en algunos lugares inesperados.

Cuando Gabriela Arakaki me invitó a conocer una colección de arte contemporáneo, no podía imaginar la sorpresa que me esperaba. Un conjunto de obras de arte peruano seleccionadas por el Sr. Gianfranco Sensi Contugi ${ }^{2}$, que celosamente conserva su esposa Rosa Amelia León. En la visita ubiqué dos objetos que evidentemente no encajaban en el acervo, eran fragmentos de estelas Chavín -una de ellas quebrada en tres- con los diseños característicos de dicha cultura. Al enterarse la señora León de la importancia de las piezas, las donó gentilmente al Museo de Arqueología y Antropología de San Marcos (MAA-UNMSM), acto realizado en memoria de su esposo.

Cuando mostramos las fotografías al equipo del MAA-UNMSM, rápidamente reconocieron uno de los fragmentos, que había sido estudiado por Julio C. Tello y publicado en Chavín. Cultura matriz de la civilización andina (1960: 213-214).

Las piezas deben haber sido rotas durante las campañas de extirpación de idolatrías, tal como lo sugirió Tello (1960: 223). Él encontró decenas de fragmentos de estelas y lápidas durante sus trabajos de investigación en el sitio arqueológico, algunas fueron enviadas al MAAUNMSM y luego derivadas al Museo Nacional de Aqueología, Antropología e Historia del Perú (MNAAHP). Pero la mayor parte se quedó en Chavín y conformaron la colección del museo local fundado por Tello.

Desgraciadamente la historia de los museos y sitios arqueológicos peruanos parece estar cubierta por la sombra del

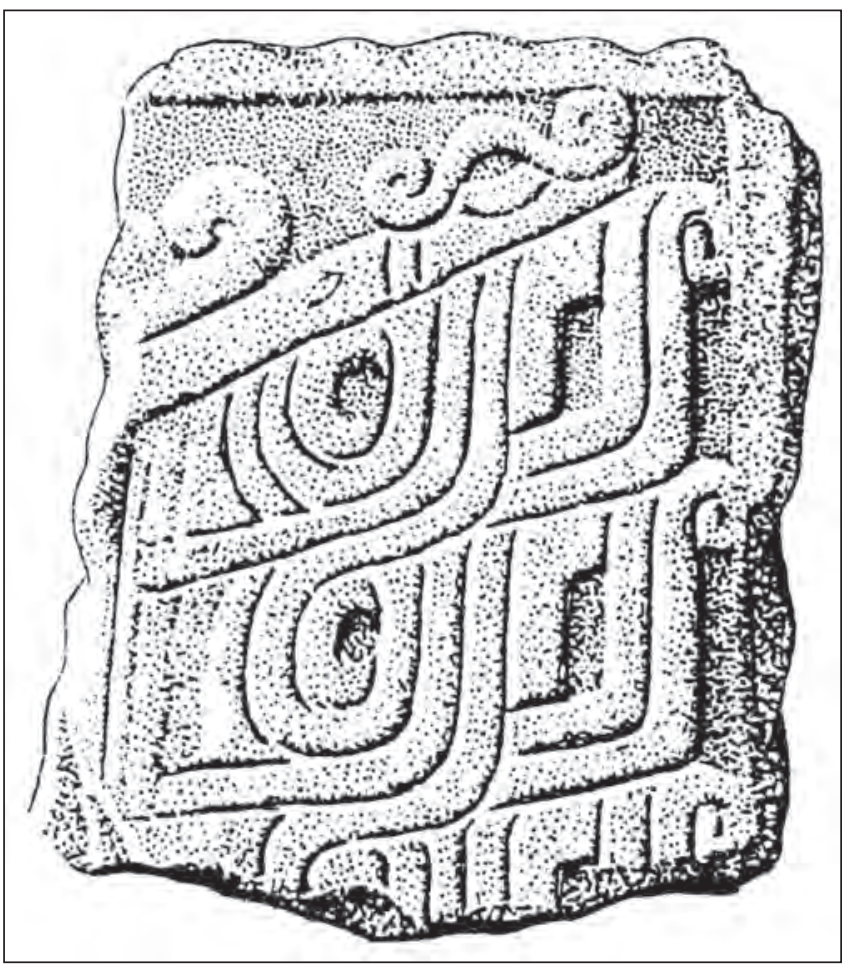

Figura 1. Julio C. Tello (1960, fig. 45).

1 Huacos.

2 Doctor en economía. Ciudadano italiano radicado en el Perú. Falleció en 1999. 


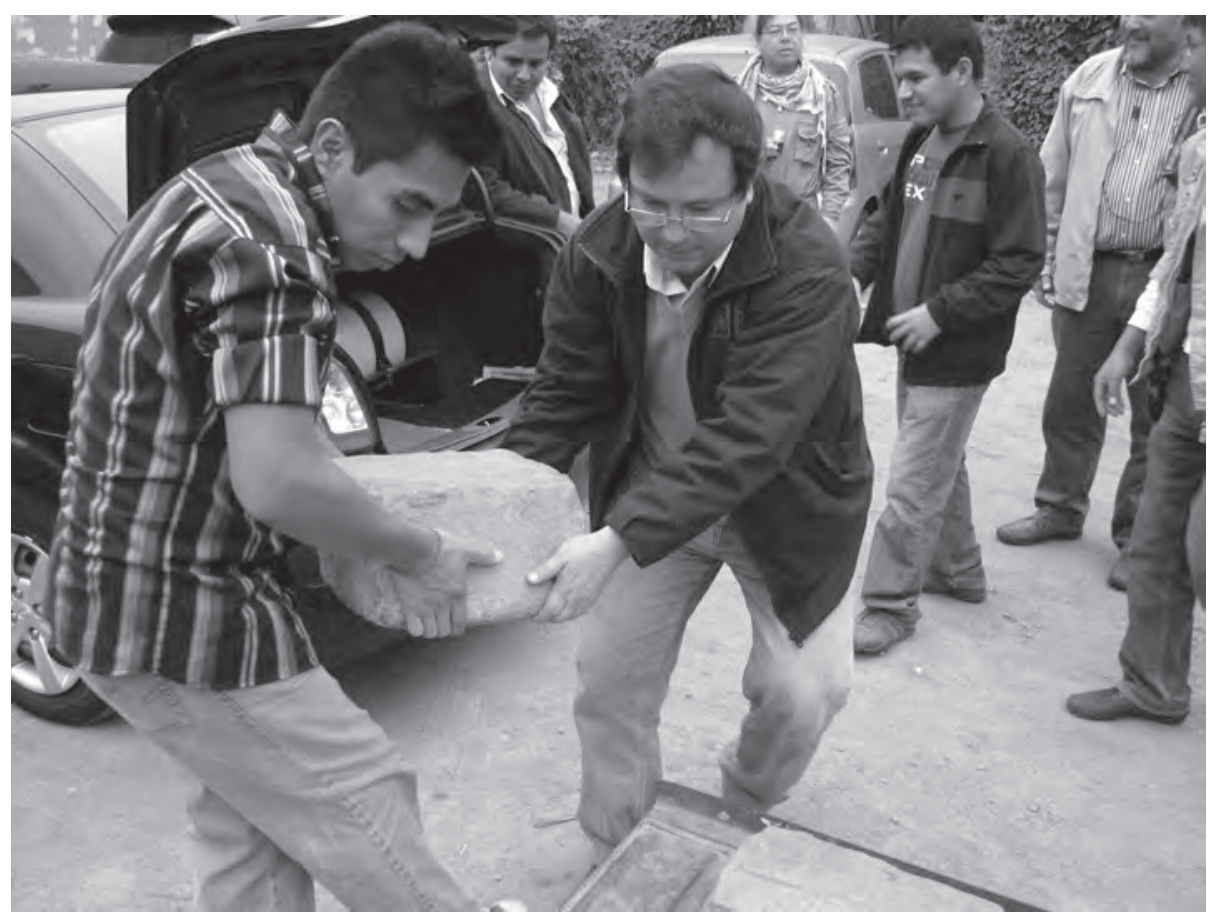

Figura 2.

infortunio. El Museo Nacional saqueado por las tropas chilenas, el Museo Nacional de Arqueología y Antropología asaltado en 1981 o el Museo de la Nación disminuido para ser convertido en centro de convenciones el año 2008. En cuanto a Chavín, el verdugo fue la naturaleza. El aluvión de 1945 destruyó su museo de sitio y acabó con esta primera colección de litoescultura. El acervo fue arrastrado al río Mosna.

Pero ahora tenemos a la vista una pieza que se salvó del desastre, y que tras un itinerario que no conocemos, ha vuelto a ser de dominio público gracias a la generosidad de la más reciente propietaria.

Las litoesculturas halladas corresponden a lo que tipológicamente se clasifica como una estela: "Estos monolitos van decorados en sólo una de sus caras; son paralelepípedos de constitución tabloide.» (Kauffmann 2002: 198). En ambos casos la materia prima es granodiorita compuesta de granos de cuarzo y feldespato. El color es gris claro. Se ha empleado las técnicas del piqueteado y pulido para grabar las imágenes en plano relieve. ${ }^{3}$

A continuación se describirá cada una de las piezas.

\section{DESCRIPCIÓN}

\section{PIEZA 1}

Al parecer se trata de la esquina superior izquierda de una estela. Se conserva el marco. La iconografía muestra parte de un ala, con grandes plumas y pequeñas volutas. También hay una figura serpentiforme; Tello la describió como una pluma rémige (remera) transformada en ofidio. Fue hallada en el sitio de Gotush en 1941. Las medidas son: largo $28 \mathrm{~cm}$, ancho $31 \mathrm{~cm}$ y espesor $20,8 \mathrm{~cm}$.

3 Juan Yataco. Ficha de registro de la piezas en el MAA-UNMSM. 


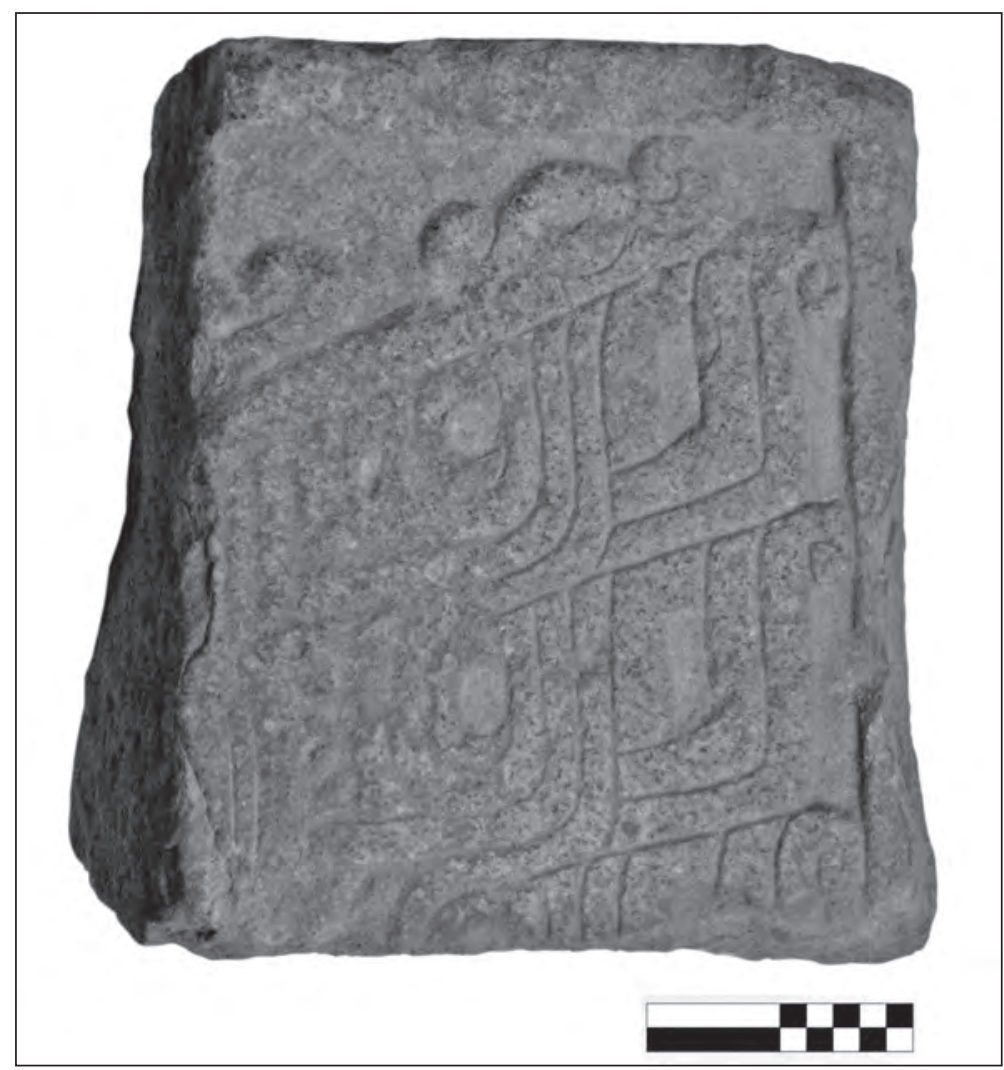

Figura 3.

\section{PIEZA 2}

En este caso también hay restos del marco. Se distingue una boca con dientes triangulares y dos colmillos grandes; una gran cola ornitomorfa; parte de una pata con garra de águila y una serpiente claramente representada, que cae entre las plumas y la pata. Además se observa un elemento alargado que se ubica en diagonal, debe tratarse de otro ofidio pero tiene la cabeza erosionada. Las medidas son: largo $45 \mathrm{~cm}$, ancho 35,5 cm y espesor 15,6 cm. Aquí se conjugan partes de tres seres de notable importancia en el imaginario chavín: jaguar, ave rapaz y serpiente.

En ambos casos se trataría de seres míticos que sirven a las divinidades más poderosas. En ese sentido, John Rowe consideraba de alta jerarquía al Dios de las Varas (Estela de Raimondi) y sus servidores serían los llamados «ángeles» o seres míticos con rasgos ornitomorfos (1972: 269-270).

\section{EXPRESIONES DEL ARTE ChAvíN}

En las dos piezas encontramos las características enunciadas por los estudiosos del arte chavín: es figurativo y con un discurso visual pletórico de metáforas y simbolismos recurrentes, tal como lo ha definido Rowe:

«El arte de Chavín es fundamentalmente representativo, pero su sentido representativo queda oscurecido por las convenciones que rigen el estilo chavín y en muchos casos, por el hecho de que los detalles representativos no se representan directamente sino de una manera figurada o metafórica» (1972: 257). 


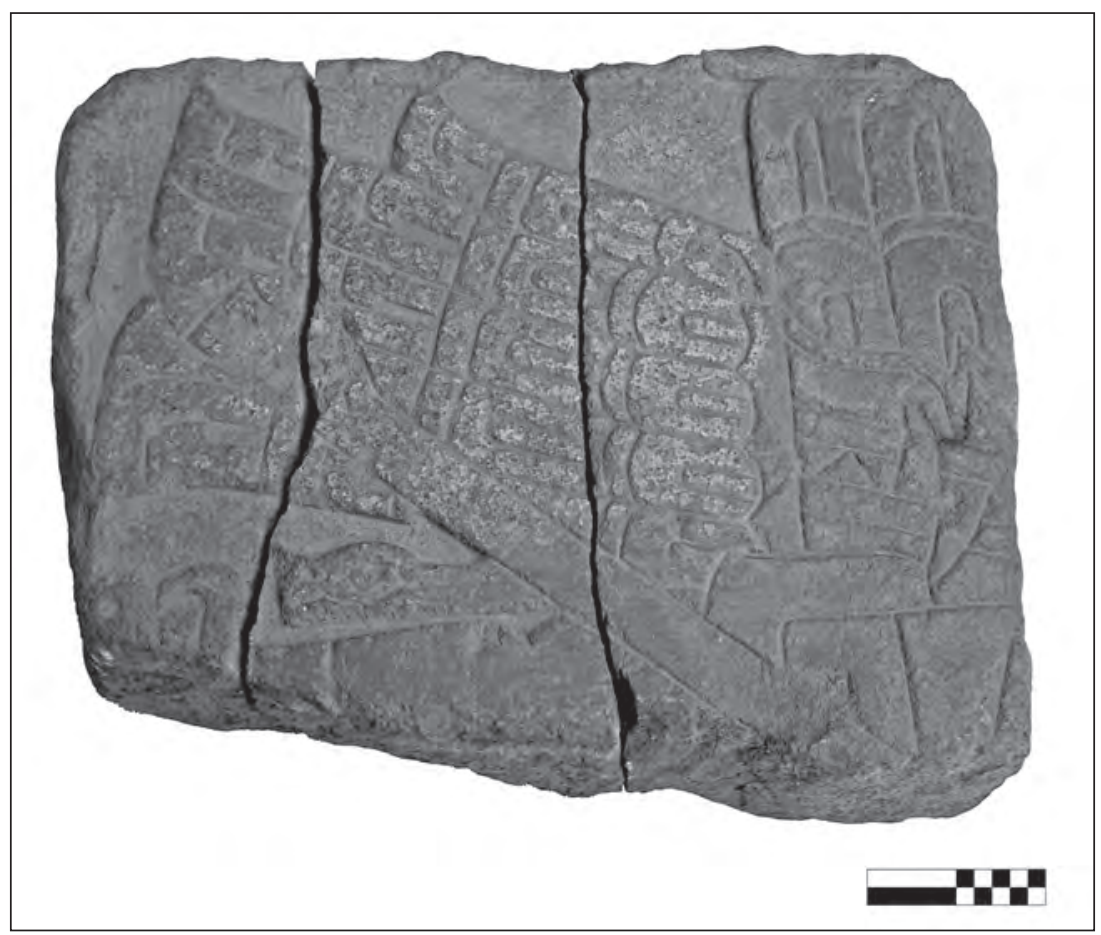

Figura 4.

La litoescultura Chavín se expresa mediante relieves sobre superficies planas y sólo en segundo lugar mediante la escultura en bulto redondo: "[...] la tarea que los artistas de Chavín se asignaron fue la de hacer un dibujo lineal sobre una superficie plana, o a lo menos una superficie tratada como si fuera plana» (Rowe 1972: 257).

Una afirmación que coincide con las observaciones de Luis Lumbreras:

«El arte lítico chavinense no es propiamente escultórico, pese a que existen más de cien esculturas de cabezas monstruosas, humanas, de animales, etc. Se trata en realidad de un manejo de superficies planas, en donde se graban imágenes relacionadas con el culto. Es un arte asociado a la arquitectura, aunque algunas piezas son obviamente independientes de ella, como es el caso del ídolo principal, que si bien está dentro del templo, obviamente fue esculpido con independencia de una función de columna, enchape de muro, viga, cornisa o algo similar; ocurre igual con piezas como el Obelisco Tello» (1989: 33 y 36).

Respecto a la técnica, Tello hizo una explicación bastante detallada:

«La figuras simbólicas aparecen en unos casos grabadas mediante simples incisiones o surcos; en otros se excava o rebaja el fondo, de modo que se destacan en planorrelieve; con frecuencia se suavizan los aristas o redondean los contornos y se profundiza más el fondo para que la figura se destaque en altorrelieve; o bien ciertos detalles se modelan aun debajo del nivel de la superficie de la piedra, de modo que aparecen en bajorrelieve; y por último, se completa el contorno de la figura en todas sus dimensiones para obtener la escultura en bulto» (1960: 159-160).

Una obra de arte es un producto de la creatividad humana, mediante el cual un hombre -o un grupo- expresa y comunica la complejidad de su mundo interior o de su entorno social o natural. El 
producto provoca experiencias estéticas en los espectadores más allá del tiempo de vida de su creador. En este caso estamos ante unos fragmentos que en sus dimensiones humana, técnica, estética y simbólica, brindan una idea del poderoso efecto del arte chavín y testimonian la compleja cosmovisión de una cultura ancestral.

\section{Agradecimientos}

El autor desea expresar su agracimiento a las siguientes personas: Gabriela Arakaki, Rosa Amelia León, Juan Yataco, Christian Altamirano y Juan Roel.

\section{BiBLIOGRAFÍA}

\section{KAUFFMANN, Federico}

2002 Historia y arte del Perú Antiguo 2. Lima: La República - Peisa.

LUMBRERAS, Luis

1989 Chavín de Huántar en el nacimiento de la civilización andina. Lima: INDEA.

RIVERO, Mariano Eduardo de.

1841 Antigüedades peruanas. Parte primera. Lima.

ROWE, John

1972 «El arte de Chavín. Estudio de su forma y su significación artística». En: Historia y Cultura 6: 249276. Lima.

TELLO, Julio C.

1960 Chavín. Cultura matriz de la civilización andina. Obra publicada con la revisión de Toribio Mejía Xesspe. Lima: UNMSM.

VÁZQUEZ DE ESPINOZA, Antonio

1948 Compendio y descripción de las Indias Occidentales. Washington: Smithsonian Institution. 